\title{
Nilai Sufistik Pada Inskripsi Pintu Makam Sunan Kudus
}

nfn. Masyhudi

Keywords: inscription, calligraphy, islam, tomb, Central Java

\section{How to Cite:}

Masyhudi, nfn. Nilai Sufistik Pada Inskripsi Pintu Makam Sunan Kudus. Berkala Arkeologi, 15(2), 10-24. https:/ / doi.org/10.30883/iba.v15i2.657

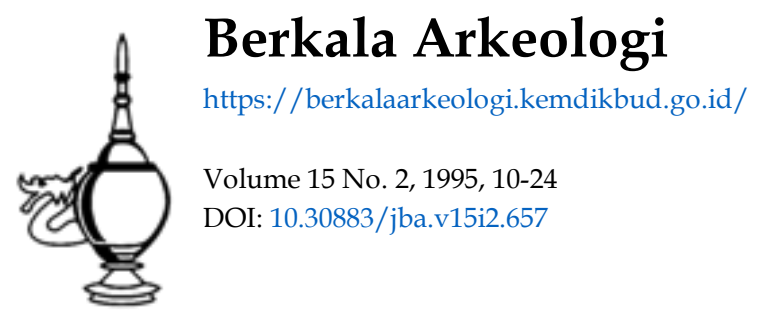

\section{c) (i) (2)(2)}

This work is licensed under a Creative Commons Attribution-NonCommercial-ShareAlike 4.0 International License. 


\title{
NILAI SUFISTIK PADA INSKRIPSI \\ PINTU MAKAM SUNAN KUDUS
}

\author{
Masyhudi \\ (Balai Arkeologi Yogyakarta)
}

\section{Pendahuluan}

Islam adalah suatu agama yang ajaran-ajarannya didasarkan pada wahyu Tuhan yang disampaikan kepada umat manusia melalui Rasul Allah (Muhammad saw) Ajaran-ajaran tersebut pada hakekatnya meliputi berbagai segi kehidupan manusia (Nasution,1984:24). Antara berbagai ajaran Islam yang ada, yang terpenting dan mendasar adalah ajaran tauhid, yaitu pengakuan terhadap Tuhan Yang Maha Esa. Ajaran yang lain adalah manusia terdiri dari badan (jasmani) dan roh yang berasal dari Tuhan dan akan kembali kepada-Nya.

Tuhan adalah suci dan roh yang datang dari Tuhan dan menjadi urusan Tuhan (QS Al-Isra':85) juga suci, ia akan kembali ke asalnya di sisi Tuhan kalau ia tetap suci. Oleh karena itu, harus selalu diupayakan agar roh tetap suci, sehingga manusia yang didasari oleh kesucian roh tersebut, perilaku dalam hidupnya menjadi baik. Ajaran mengenai hal ini terhimpun dalam bentuk trablun minallah dan hablun minannaas, yaitu hubungan secara vertikal antara manusia dengan Tuhannya dan hubungan secara horisontal antara sesama manusia dan antara manusia dengan lingkungannya. Hal ini tercermin dalam bentuk ibadat (sholat, zakat, puasa haji dan ajaran-ajaran moral atau akhlak Islam).

Sehubungan dengan hal itu, yang mendasari konsep ajaran asauwuf/sufi adalah adanya segolongan umat Islam yang merasa tidak puas dengan cara formal yang terdapat dalam ibadat sebagai upaya untuk mendekati Tuhan. Dalam arti lain hidup yang diperoleh dengan cara ibadat biasa belum memuaskan kebutuhan spiritual mereka. Oleh sebab itu mereka berupaya mencari jalan yang dianggap dapat membawa mereka lebih dekat kepada Tuhan, sehingga mereka merasa dapat melihat Tuhan dengan hati sanubari. Ajaran mengenai hal ini terdapat dalam "Mistisisme" (tasamwuf). Jenjang kehidupan masyarakat yang demikian dapat diketahui melalui sejarah serta ajaran-ajaran yang ada, sedangkan secara fisik dapat diketahui melalui fenomena-fenomena budaya melalui data arkeologis dan data sejarah

Demikian halnya, dengan inskripsi yang terdapat pada pintu makam Sunan Kudus, adalah suatu bukti dari fenomena-fenomena 
budaya tersebut Inskripsi itu menunjukkan adanya kepedulian masyarakat masa lampau dalam hal budaya menulis indah. Di samping itu, ajaran yang terkandung dalam tulisan itu memiliki nilai sufistik yang sangat besar pengaruhnya tehadap perkembangan Islam, khususnya di Jawa

Meskipun tulisan di atas bangunan makam ini di kalangan umat Islam masih menjadi pro dan kontra, akan tetapi maksud penulisan tersebut adalah baik. Hal itu disebabkan adanya perbedaan pendapat yang timbul bukan dalam konteks penunaian segi aqidah, akan tetapi hanya hal yang bersifat teknis dalam tingkatan mu'amalat (Ambary, 1991:6). Selain itu, penulisan tersebut dimaksudkan juga untuk mengingatkan kepada manusia, bahwa kelak akan mengalami kematian Selain itu, bagi para peziarah yang membacanya serta mengetahui makna yang terkandung di dalamnya, akan menambah keimanannya.

Tulisan ini dimaksudkan untuk mengungkap nilai yang terkandung di dalam inskripsi yang tertera pada pintu cungkup makam Sunan Kudus, yang belum diketahui makna kandungan nilai yang tersirat didalamnya.

\section{Mistisisme di Indonesia.}

Aliran mistisisme (tasamwuf) muncul sejak agama Islam masuk di Indonesia. Secara politis, Islam masuk dan tersebar di Indonesia, sejak datang di Samudera Pasai pada abad ke-13. Beberapa teori tentang masuknya Islam ke Indonesia telah banyak dibicarakan oleh para pakar, salah satu yang terpenting adalah "Teori Tasawwur". Teori ini tersebar luas di Nusantara sebagai akibat dari kegiatan yang dilakukan oleh para sufi. Hal ini sangat menarik, karena merupakan suatu taktik yang memberikan sumbangan besar bagi kebudayan Islam di Indonesia. Kenyataan ini telah menunjukkan bahwa tasamwuf demikian mendalam pengaruhnya dalam kehidupan masyarakat Indonesia yang mayoritas beragama Islam (Abdul Hadi, 1984.97)

Di Jawa dan secara umum di indonesia, tasamwuf dapat tumbuh dengan subur, karena didukung oleh adanya sistem budaya yang bersifat eroteris, sebagaimana terdapat di dalam ajaran Hindu-Buda. Aliran Tasamwuf ini muncul mula-mula dari Sumatera pada abad ke-13 kemudian pada abad ke-15 yaitu sejak Kerajaan Islam berdiri di Jawa, dengan tokoh para wali yang berperan dalam penyebaran Islam di Jawa (Saptono, 1994/1995:33).

Tinggalan-tinggalan kuna di Indonesia, seperti hainya masjid yang memiliki corak khas Indonesia, dibangun atas dasar yagasan orang-orang di kalangan sufi. Dalam pandangan sufi terdapat kesatuan 
dari empat hal yang tak dapat dipisahkan dalam pelaksanaan ajaran islam, yaitu syari'at, tarekat, hakekat dan ma'rifat. Beberapa masjid kuna yang pada umumnya mempunyai atap tumpang. Bentuk atap tumpang yang berasal dari masa pra Islam ini, kemudian diberi makna simbolis baru sehingga menjadi budaya khas Islam. Pemberian makna simbolis dilakukan dengan mengubah dan menyingkirkan unsur-unsur yang bertentangan dengan ajaran Islam, sehingga lahir konsepsi baru dalam bidang arsitektur. Dengan demikian, arsitektur mengalami pengislaman sebagaimana terjadi di tempat-tempat lain. Hal ini memberikan bukti bahwa Islam datang ke Indonesia tidak menghancurkan kebudayaan yang telah ada, bahkan memanfaatkannya untuk membentuk sesuatu yang baru.

Selain di bidang arsitektur, sumbangan Islam yang cukup besar bagi perkembangan Kebudayaan Islam di Indonesia adalah dalam bidang Bahasa dan sastra yang berkaitan dengan kegiatan para sufi. Dalam sejarah sastra Islam yang berkembang di negara-negara Islam, para sufilah yang membangkitkan kesusasteraan, yaitu setelah kebangkitan sastra Arab dan Persi yang dimulai dengan kebutuhan para sufi untuk mengekspresikan pengalaman dunia mistiknya yang memiliki kualitas puitis dan estetis.

Dengan berkembangnya bahasa dan sastra Islam, maka muncullah berbagai gagasan baru. Al-Quran sendiri dengan segala keindahannya telah menantang sastrawan-sastrawan muslim agar dapat melahirkan karya sastra yang bernilai tinggi, seperti disebutkan dalam Al-Quran:

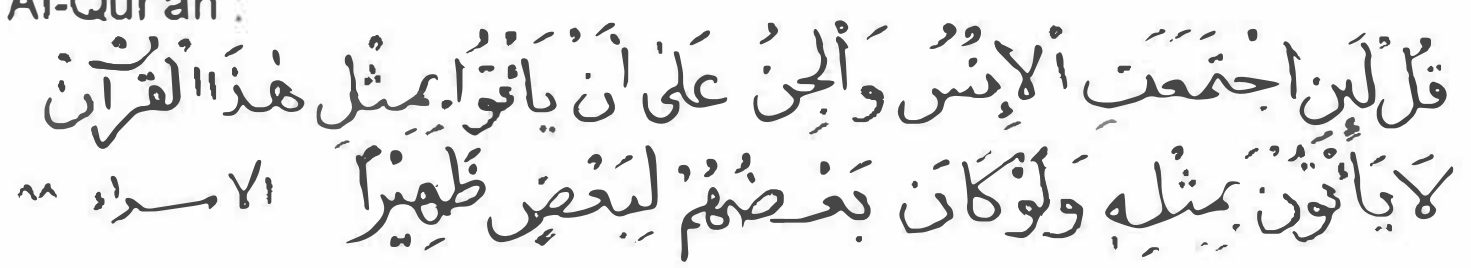

"Katakanlah: Sesungguhnya jika manusia dan jin berkumpul unluk mengatakan yang serupa al-Quran ini niscaya mereka tidak akan dapat membuatnya, biarpun sebagian mereka membantu sebagian yang lain"(QS. ALIsra':88)

Arti pengalaman estetika dalam kebudayaan Islam sebagaimana yang terpancar dalam ajaran tasamwuf adalah salah satu bentuk pengenalan sifat-sifat llahi, sehingga setiap seni akan selalu tertuju kepada Allah, karena seni merupakan sesuatu yang tak dapat dicari, karena keindahan tak dapat dipisahkan dari inspirasi (ilham/vision). Ilham, yaitu sejenis wahyu yang tingkatannya lebih rendah dan dapat diberikan kepada manusia biasa yang bukan nabi.

Di sisi lain seni menulis indah (kaligrafi) adalah salah satu budaya kebesaran umat Islam. Hal ini terbukti pada keanekaragaman 
hiasan lukisan yang memenuhi masjid-masjid dan bangunanbangunan lain yang dituangkan dalam bentuk paduan ayat-ayat AlQur'an ataupun kata-kata hikmah (Sirajuddin, 1985:4)

Di Indonesia, setelah Islam datang dan berkembang dengan subumya, kaligrafi atau tulisan indah ini, bukan saja termuat di masjidmasjid, tetapi juga di bangunan-bangunan lain seperti halnya bangunan makam.

\section{Inskripsi Makam Sunan Kudus}

Dalam tamaddun (peradaban) Islam yang berkembang di indonesia, kaligrafi Arab merupakan suatu elemen yang memiliki peranan cukup penting. Perkembangan tersebut dapat dilihat dan diamati dari epigrafi (inskripsi) pada makam-makam kuna yang tersebar di berbagai tempat di Indonesia yang pada umumnya makam-makam tersebut merupakan tempat pemakaman raja-raja atau masyarakat yang memiliki peranan yang penting di masa hidupnya.

Budaya menulis indah di Indonesia, perkembangannya telah mengalami pergeseran, yaitu pada tema-tema penulisan yang dulunya para seniman keraton menulis dengan tema keraton, tetapi dalam perkembangannya tulisan tersebut tumbuh dan mengacu kepada totalitas ajaran yang hakiki, yakni sufisme. Adapun yang menjadi sumber tulisan indah (kaligrafi) adalah Al-Qur'an dan Hadits Rasul saw, yang mengarah kepada pemilihan lafadz-lafadz atau kata-kata yan' disesuaikan dengan tuntutan suasana.

Inskripsi yang terdapat pada pintu makam Sunan Kudus merupakan salah satu wujud kepedulian masyarakat masa lampau dalam hal kreatifitas seni dan melestarikan budaya menulis indah. Selain itu, yang lebih penting dalam inskripsi itu adalah nilai yang terkandurig di dalamnya. Pada umumnya tulisan-tulisan tersebut diambil dari berbagai sumber, yaitu ayat Al Duran. Kalimah Thayyibah/Kalimah Tauhid, dan Asma'ul Husna.

\subsection{Ayat Al-Quran}

Kutipan ayat Al-Quran yang terdapat pada inskripsi makam Sunan Kudus diambil dari Surat Al-Baqarah ayat 255 yang dikenal dengan Ayat Kursi.

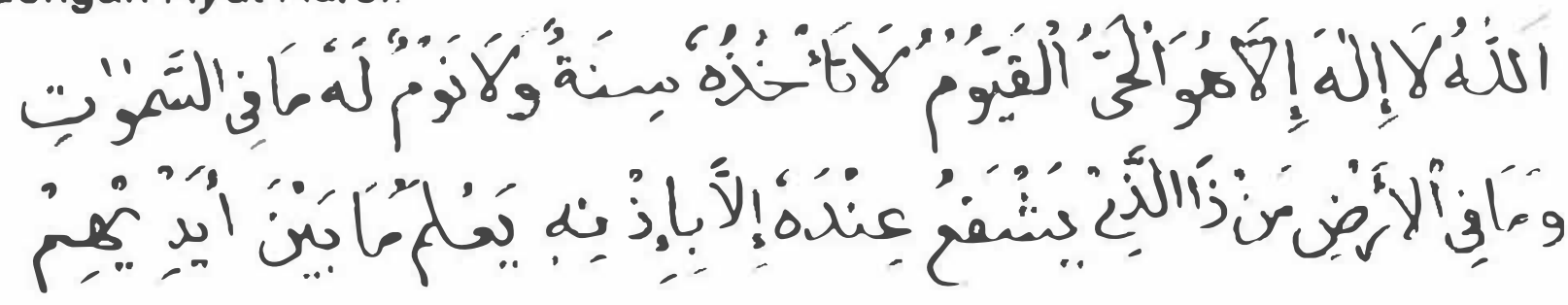




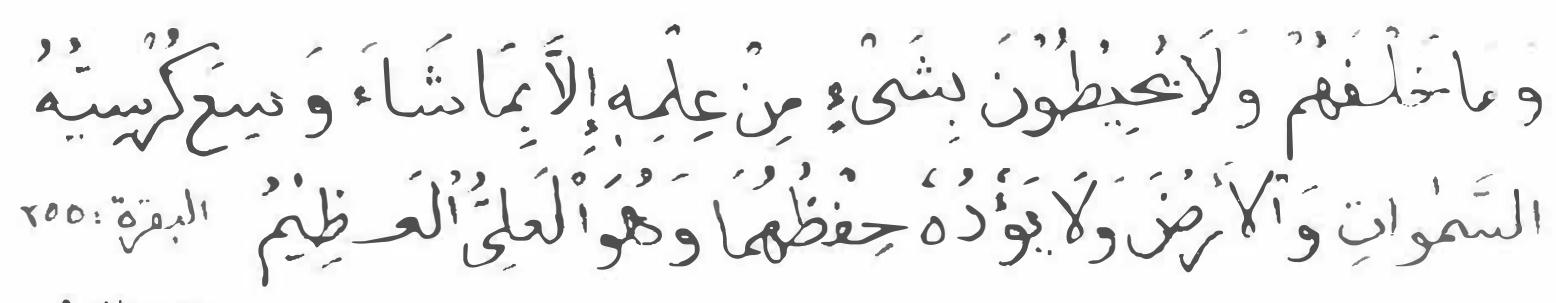

Artinya:

"Allah, idak ada Tuhan (yang berhak disembah) melainkan Dia Yang Hidup kekal lagi terus menerus mengurus makhluk-Nya. tidak mengantuk dan tidak tidur. Kepunyaan-Nya apa yang di langit dan di bumi. Tiada yang dapat memberi syałaat di sisi Allah tanpa izin-Nya. Allah mengetahui apa-apa yang ada di hadapan mereka dan di belakang meraka dan mereka tidak mengetahui apa-apa dari ilmu Allah, melainkan apa yang dikehendaki-Nya. Kursi (kekuasaan Allah) meliputi langit dan bumi. Dan Allah tidak merasa berat memelihara keduanya, dan Allah Maha Tinggi lagi Maha Besar".

Ayat tersebut di atas menunjukkan kebesaran kekuasaan dan kesempurnaan Allah, sehingga hanya Allah-lah yang berhak untuk disembah

Dengan demikian, jika ayat tersebut di atas dapat di pahami dan seterusnya diyakini dan diamalakan, maka iman seseorang menjadi semakin kuat. Dibaca dengan baik saja tanpa mengetahui makna dan maksudnya, sudah diperoleh pahala dari Allah bagi yang membacanya. Bagi orang yang tidak dapat membaca, mendengarkan pun, pahalanya sama dengan orang yang membacanya.

\subsection{Kalimah Thayyibah/Kalimah Tauhid.}

Kalimah Tauhid adalah suatu pengakuan keyakinan tentang keesaan Tuhan (Allah). Kalimat ini berfungsi untuk memperbaharui iman seseorang, karena iman seseorang dapat terjadi secara pasang-surut. Dengan mengucap kalimat tauhid tersebut, maka iman seseorang telah terbaharui.

Beberapa ahli tafsir al-Qur'an al-Karim berpendapat, bahwa yang dimaksud Kalimah Tauhid/Kalimah Thayyibah tersebut adalah "La llaaha illallah " yang artinya tidak ada Tuhan selain Allah Dalam alQur'an al-Karim, Surat Ibrahim ayat 24 dan surat Faathir ayat 10 disebutkan sebagai berikut

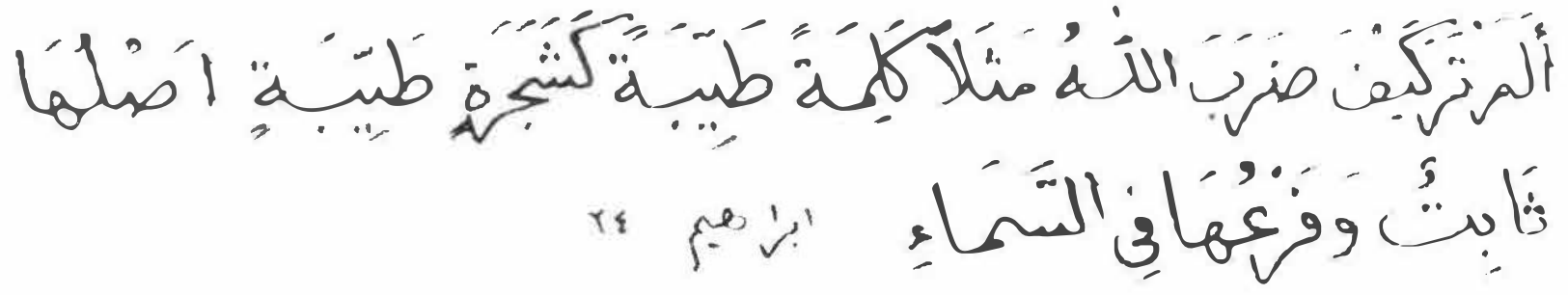


Tidakkah kamu perhatikan bagaimana Allah telah membuat perummpamaan kalimat yang baik (Laa llaaha illallah), seperti pohon yang baik, akarnya teguh dan cabangnya menjulang ke langit (Q.S Ibrahim 24)

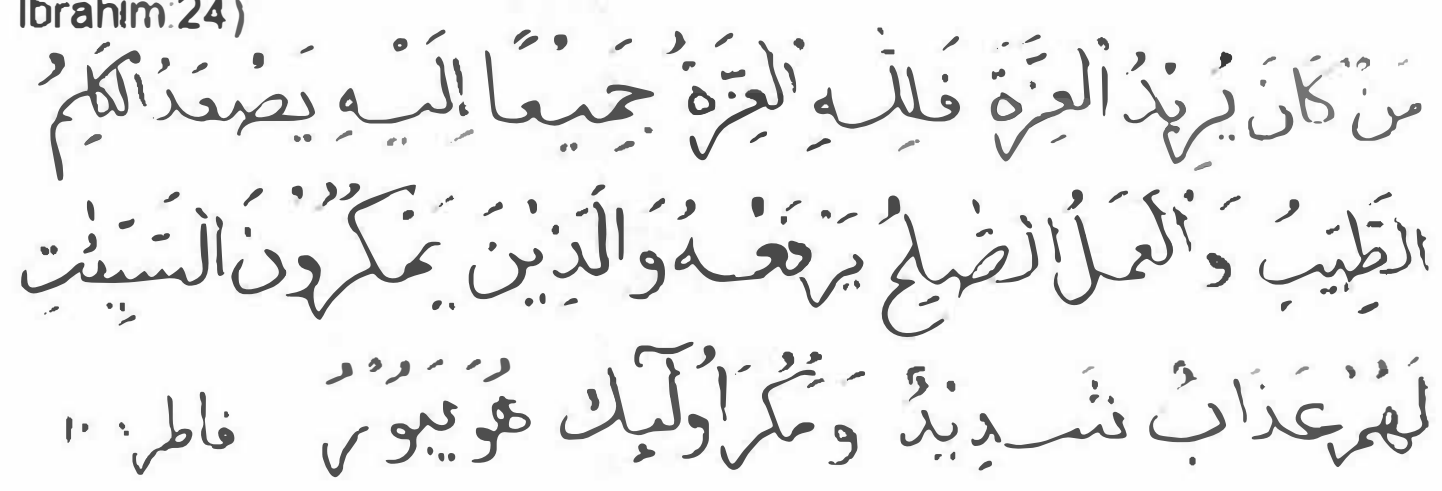

Barang siapa yang menghendaki kemuliaan, maka bagi Allah-lah kemuliaan itu semuanya. Kepada-Nyalah naik perkataan-perkataan yang baik (Laa llaaha illaliah) dan amal yang sholeh dinaikkannya Dan orang-orang yang merencanakan kejahatan, bagi mereka adzab yang keras dan rencana jahat mereka akan hancur (CS. Faathir: 10)

Kalimah Thayyibah yang ada di Cungkup Makam Sunan Kudus terdapat di bagian atas pintu kanan (timur) yaitu lafadz llaaha illallah). Sementara itu lafadz " " (Laa Rasulullah) berada di bagian atas pintu kiri (barat). Tulisan tersebut dimaksudkan agar setiap orang yang membacanya senantiasa menyadari dan mengakui akan keesaan Allah dan kerasulan Muhammad saw, serta ikut memperbaharui imannya.

\subsection{Asma'ul-Husna.}

Asma'ul-Husna adalah nama-nama yang diambil dari sifat Tuhan al-Husna (baik). Hal ini dikarenakan nama-nama Allah mengandung arti mensucikan, mengayungkan, memuliakan dan lain-lain, sementara itu al-Husna sendiri memiliki makna lebih, seperti misalnya Maha sempurna, Maha Besar, dan Maha Indah.

Jumlah nama dan sifat-sifat Allah sangat banyak, tetapi dari yang banyak tersebut ada yang diketahui dan ada yang tidak diketahui oleh manusia. Dalam Hadits Nabi saw yang diriwayatkan oleh al-Turmudzi, dari Abu Hurairah disebutkan bahwa Allah swt, mempunyai 99 nama. $\mathrm{Hal}$ ini bukanlah berarti bahwa Allah swt, tidak memiliki nama lain selain nama-nama tersebut. Ini terbukti dengan adanya beberapa perbedaan pendapat tentang nama-nama (sifat) yang terdapat di dalam 
Asma'ul-Husna meskipun dalam jumlah yang tidak berbeda. Selain itu. Asma'ul-Husna didasarkan juga pada Al-Quran al-Karim, yaitu dalam Surat al-Isra' ayat 110;

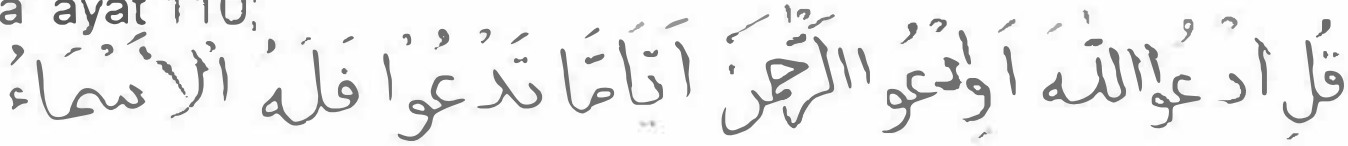

$$
\begin{aligned}
& 11 \text { : : stur }
\end{aligned}
$$

"Katakaniah! Serulah Allah atau serulah Ar-Rahman. Dengan nama yang mana saja kamu seru. Dia mempunyai Al-Asma'ul-Husna (nama-nama yang baik)"

Asma'ul-Husna yang terdapat pada inskripsi pintu makam Sunan Kudus didahului dengan kalimat;

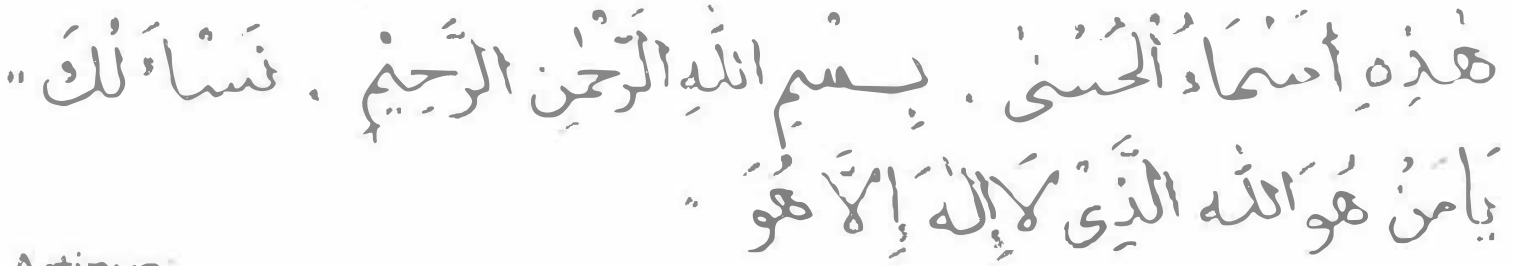

Artinya

"Ini adaiah Asma'ul-Husna. Dengan nama Allah Yang Maha Pemurah lagi Maha Penyayang. Kami memohon kepada-Mu wahai Allan, yang tidak ada Tunan selain Cia".

Kemudian kaliniar tersebut dikuti oleh lafadz-lafadz (sifat-sifat) Tuhan, seperti dalarn tabel berikut.

\begin{tabular}{|c|c|c|c|}
\hline NO & TRANSLITRASI & TARJAMAHIARTI & $\begin{array}{l}\text { LAFADZ-LAFADZ } \\
\text { ASMA'UL-HUSNA }\end{array}$ \\
\hline $9 !$ & Ar-Rahman & Maha Pemurah & 01 \\
\hline 02 & Ar-Rahim & Maha Perryayang & 02 \\
\hline 03 & At Malik & Maha Merajai & 03 \\
\hline 04 & At Quddus & Maha Suci & 04 \\
\hline 05 & As-Salarn & Pernberi Keselamatan & 05 \\
\hline 06 & AL-Mukmin & Pemberi Keamanan & 06 \\
\hline 07 & At Muhaimin & Pelindung \& Pengawas & 07 \\
\hline 08 & Al-Aziz & Maha Mengalahkan & 08 \\
\hline 09 & Al-Jabbaar & Maha Perkasa & 09 \\
\hline 10 & Al-Mutakabbir & Memiliki Keagungan & \\
\hline 11 & At Khaliq & Maha Pencipta & 11. \\
\hline
\end{tabular}




\begin{tabular}{|c|c|c|c|}
\hline 12. & A-Bariy & Maha Pengada & 12 s \\
\hline 13. & Al-Mushawnir & Maha Pernoentuk & 13. \\
\hline 14. & ALGhaffar & Maha Pengamoun & 14. \\
\hline 15 & Al-Qahhar & Maha Memaksa & 15. \\
\hline 16 & ALWahhab & Maha Pemberi & 16. \\
\hline 17 & Ar-Razzaq & Maha Pemberi Rizar & 17. \\
\hline 18 & Al-Fattah & Pembuka Pintu Ratumat & 18. \\
\hline 19 & At'Alim & Maha Mengetahui & 19. \\
\hline 20 & AlQaabidh & Menahan Rizai & 20. $\dot{v}$ \\
\hline 21 & Al-Baasith & Melapangkan Rizqi & 21. \\
\hline 22 & Al-Khaafidh & Merendahkan Derajat & 22 \\
\hline 23 & Ar-Raafi & Meninggikan Derajat & 23. \\
\hline 24 & Al-Mu'izz & Maho Mermutiakan & 24. \\
\hline 25 & A-Mudzill & Maha Menghinakan & 25 \\
\hline 26 & As-Sami' & Maha Mendengar & 26 . \\
\hline 27 & Af-Bastrir & Maha Melithat & 27. \\
\hline 28 & ALHakam & Menetapkan Hukum & 28. \\
\hline 29 & Al'Adl & Maha Adid & 29. \\
\hline 30 & AtLatif & Maha Lemah Lembut & 30. \\
\hline 31 & Al-Khabir & Maha Tahu & 31. \\
\hline 32 & A-Halim & Maha Perryaniun & 32. \\
\hline 33 & Al-'Adxim & Maha Agung & 33. \\
\hline 34 & As-Syakur & Maha Pembalas Jasa & 34. \\
\hline 35 & Al-'Aliy & Maha Tinggi &, 35 \\
\hline 36 & ALKabir & Maha Besar & 36. \\
\hline 37 & ALHafidz & :Aaha Memetihara & 37. \\
\hline 38 & Af-Muqit . & Yang Memberi Makan & 38. \\
\hline 39 & Al-Hasib & Maha Menghitung & \\
\hline 40 & AJ-Jalif & Maha Sempurna & 40. \\
\hline 41 & At Karim & Maha Pemurah & 41. \\
\hline 42 & Ar-Raqib & Maha Mengawasi &, 3 \\
\hline 43 & Al-Mujib & Maha Mengabulkan & $=\sqrt{4} 43$ \\
\hline 44 & Al-Waasi' & Maha Luas & isi \\
\hline
\end{tabular}




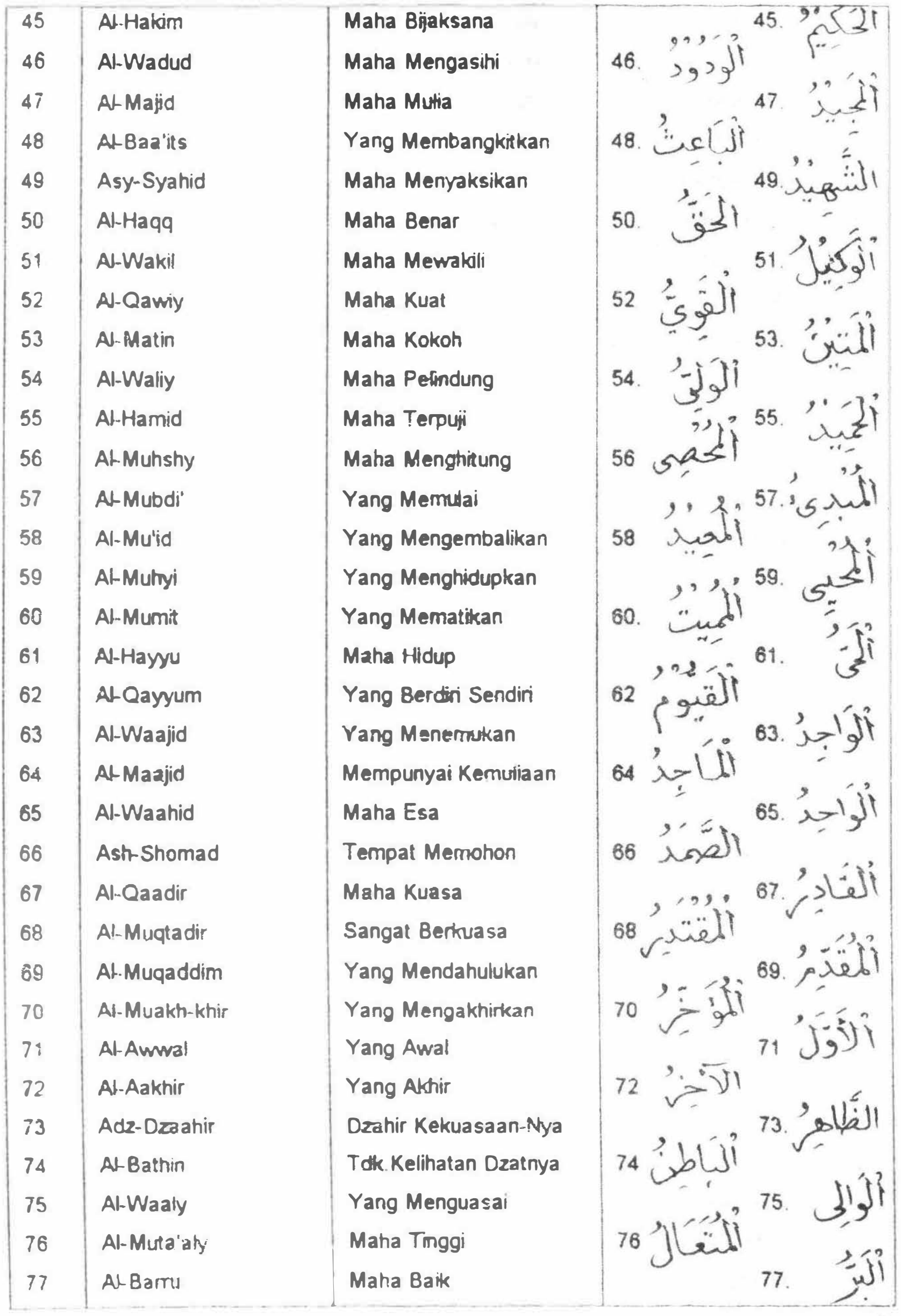




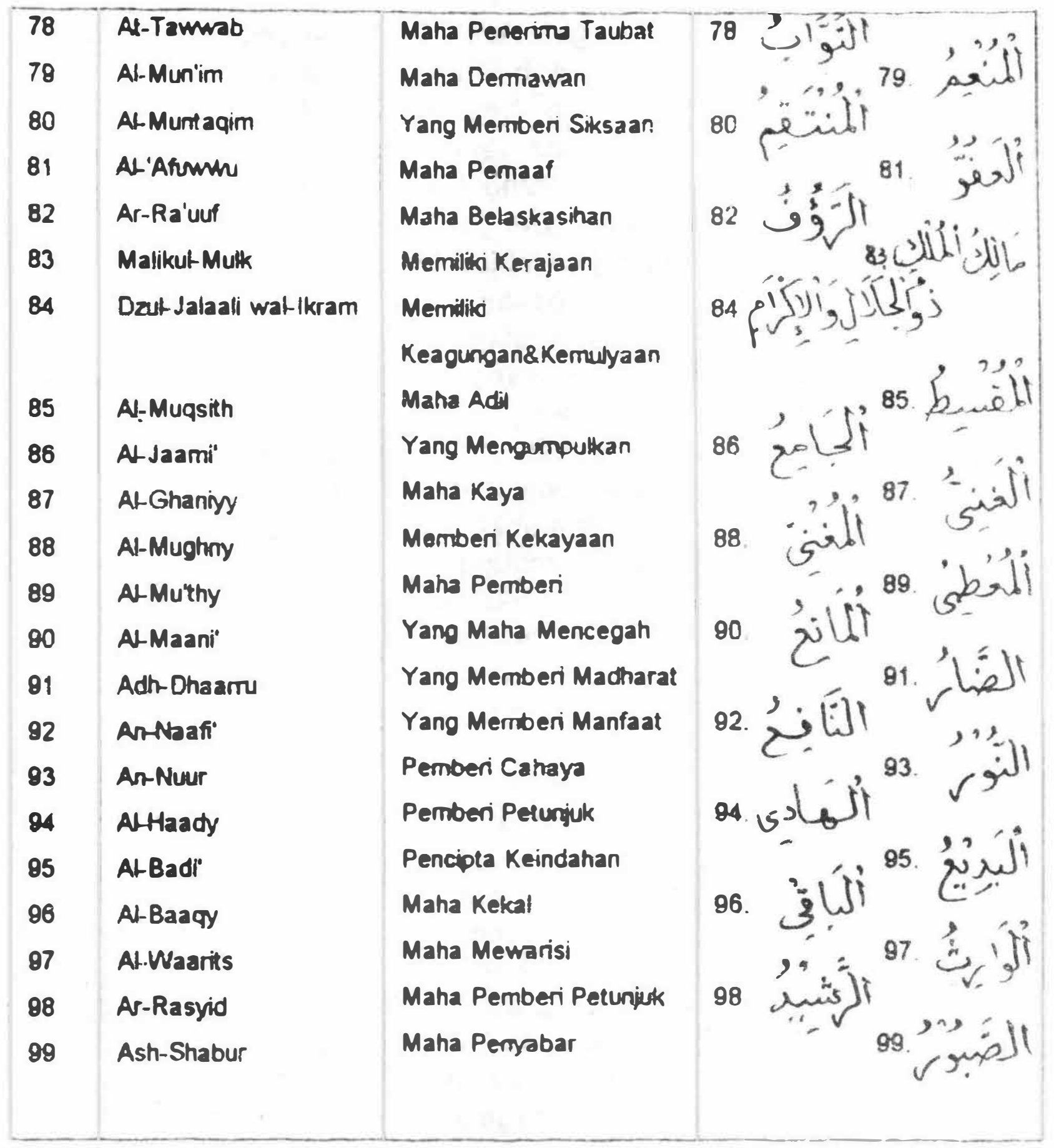

Berdasarkan hadits yang diriwayatkan oleh al-Turmudzi, dari abu Hurairah dan ayat al-Qur'an Surat Al-Isra' ayat 110 yang terurai dalam "Khasyiyah Ash-Showy 'Ala Tafsiril-Jalalain" karya Asy-Syaikh Ahmad Ash-Showy Al-Maliky, dijelaskan bahwa 99 asma Allah itu, lafadz Allah adalah termasuk dalam jumlah tersebut, karena lafadz tersebut merupakan A'dzamul-asma' (nama yang paling agung) (Al-Maliky,528).

Lain halnya dengan Asma'ul-Husna yang tertera pada inskripsi pintu makam Sunan Kudus, jumlah tersebut tidak termasuk lafadz Allah. Di samping itu dari 99 nama Allah yang terdapat pada inskripsi pintu makam Sunan Kudus, sebagaimana tersebut di atas terdapat dua 
buah lafadz yang berbeda dengan Asma'ul-Husna seperti disebutkan dalam karya Syaikh Ahmad Ash-Showy Al-Maliky, karena tidak terdapat lafadz Al-Ghafuur yang berarti Yang Maha Pengampun, melainkan ditulis dua buah lafadz yang juga merupakan sifat A!lah yang lain, yaitu Al-Mu'thy, yaitu Yang Maha Pemberi dan Al-Mun'im berarti Yang Maha Dermawan. Dengan demikian, jumlah Asma'ulHusna tersebut tidak berubah, jika lafadz Allah tidak disertakan

Asma'ul-Husno yang merupakan penjabaran dari ayat Al-Quran sebagaimana tersebut di atas adalah nama-nama yang baik yang menggambarkan sifat-sifat kesempurnaan Tuhan (Allah). Hal demikian berarti Tuhan mensucikan diri-Nya dari sifat yang mengurangi kesempurnaa-Nya. Ini dimaksudkan agar para hamba-Nya tidak raguragu memanjatkan do'a, syukur, puji-pujian kepada-Nya

Dalam ajaran Islam, diperintahkan untuk mengagungkan Tuhan (Allah), baik dengan perkataan maupun dengan perbuatan. Secara teknis mengagungkan Tuhan itu adalah sebagai berikut;

1. Mengagungkan Tuhan (Allah) sut pada dzat-Nya dengan mengi'tikadkan bahwa Allah itu wajib adanya, dzat-Nya sendiri ada tidak karena sesuatu yang lain, dan Dia tidak memerlukan sesuatu dari wujud ini.

2. Mengagungkan Tuhan pada sifat-sifatnya dengan mengi'tikadkan bahwa hanya Dialah yang memiliki segala sifat kesempurnaan.

3 Mengagungkan Tuhan pada "perbuatan-Nya" yaitu dengan mengi'tikadkan bahwa tidak ada sesuatu pun yang terjadi di alam semesta ini, melainkan sesuai dengan kehendak-Nya.

4. Mengagungkan Tuhan pada hukum-hukum-Nya, yaitu dengan mengi'tikadkan bahwa hanya Dialah yang menjadi penguasa yang dita'ati di alam semesta ini serta pada-Nya terdapat perintah dan larangan. Tidak ada seorang pun dan sesuatu pun yang dapat membatasi dan membatalkan segala ketentuan-Nya.

5 Mengagungkan pada nama-nama-Nya, yaitu menyeru dan menyebut Allah dengan nama-nama yang baik (Asma'ul-Husna).

Dari inskripsi sebagaimana terdapat pada pintu makam Sunan Kudus tersebut, dapat diambil suatu pengertian bahwa inskripsi tersebut memiliki nilai-nilai ajaran yang sangat dalam yang bersumber kepada Al-Quran dan As-Sunnah. Kemudian ajaran itu disampaikan para ulama ataupun para tokoh penyebar Islam. Secara eksplisit ajaran-ajaran yang terdapat pada inskripsi tersebut adalah mengajak serta mengingatkan kepada umat manusia, khususnya bagi yang membacanya, agar senantiasa berdo'a kepada Tuhan (Allah) dengan nama-nama yang baik (Asma'ut-Husna). Lebih jauh diharapkan 
seseorang dapat memiliki sifat-sifat baik tersebut yang terjadi pada diri manusia. Dengan demikian jadilah manusia yang selamat baik di dunia maupun diakhirat.

\subsection{TanbihiPenjelaan dari sifat-sifat Tuhan (Asma'ul-Kusna)}

Di bawah Asma'ul-Husna yang berjumlah 99 iersebut, yaitu setelah lafadz yang terakhir (Ash-Shabur) yang berarti Maha Penyabar, masih terdapat serangkaian tulisan yang terdiri dari beberapa baris yang berisi tentang penjelasan dari sifat-sifat Tuhan (Asma'ul-Husna), yaitu:

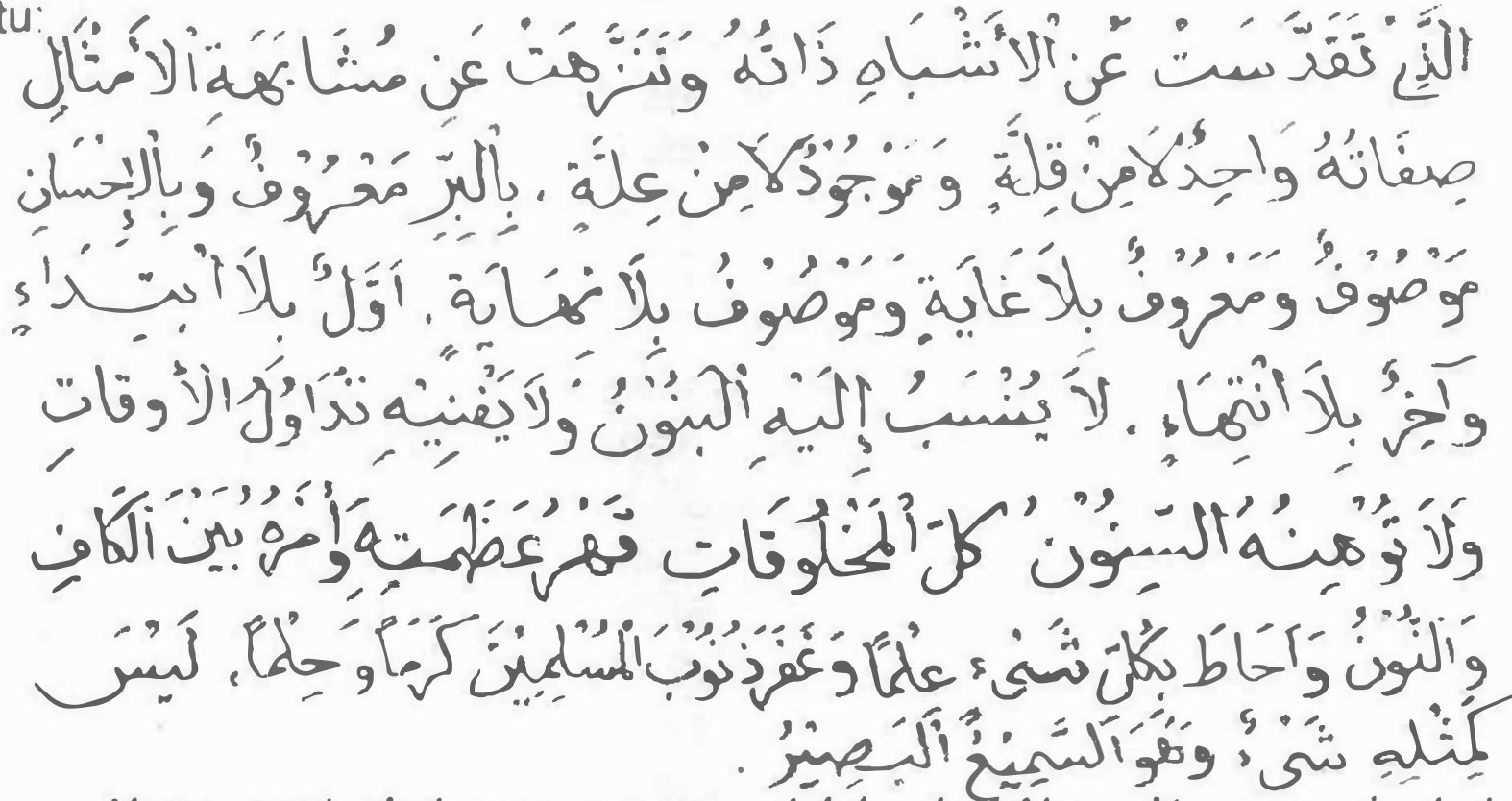

Yang suci dari persamaan adakah dzal-Nya, Yang suci dari penyerupaan adalah sifat-Nya, Yang satu lidak kurang, Yang wujud tanpa sebab akibat Yang segala kebaikan-Nya adalah Ma'ruf, kedermawanan dan kemurahan hati adalah sifat-Nya, Kema'rufanNya tiada batas akhir, sifat-sitat-Nya tiada akan habis, Yang awal tak berpermulaan, Yang akhir tak berkesudahan. Yang tak berketurunan, Yang tidak akan rusak oleh peredaran waktu. tidak akan lemah, (Wa ahaatha bi-kulli syay'in ilma) dan ilmu Allah benar-benar meliputi segala sesuatu, (Q.S. Ath-thalaq.12) Yang mengampuni dosa-dosa kaum muslimin dengan ramah dan senang-hati, Tak sesuatupun yang serupa dengan Dia, dan Dia-lah Yang Maha Mendengar lagi Maha Melihat (Q.S. Asy-Syuu-ra:11)

\subsection{Doa-Doa}

Do'a yang terdapat pada inskripsi pintu makam Sunan Kudus berada di bagian bawah pintu sebelah kiri, atau di bawah penjelasan sifat-sifat Tuhan sebagaimana tersebut di atas. Do'a-do'a tersebut, sebagian merupakan kutipan dari potongan ayat Al-Qur'an yaitu 


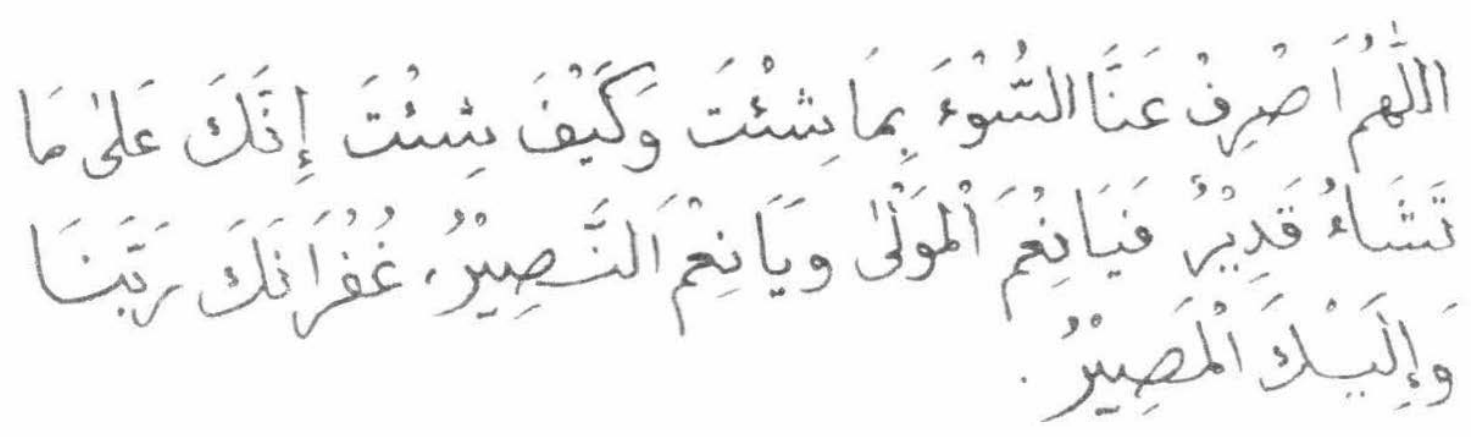

"Ya Allah hindarkanlah kami dari hal-hal yang tidak baik (kejahatankejahatan) yang (jdak menjadi kehendakmu. Sesungguhnya Engkau Maha Kuasa terhadap apa-apa yang Engkau kehendaki, Wahai dzat yang sebaik-baik pelindung dan sebaik-baik penolong. Ampunilah kami ya Tuhan kami, dan kepada Engkaulah tempat kami kembali.

\section{Kesimpulan}

Sederetan tulisan yang terdiri atas beberapa baris pada inskripsi pintu makam Sunan Kudus, yang semua ditulis dengan gaya Khat Naskhi, adalah budaya masyarakat masa lalu yang memiliki nilai sufistik. Hai ini tampak pada isi dan materi yang terdapat pada inskripsi tersebut, yaitu kutipan ayat-ayat al-Quran yang berfungsi sebagai sumber ajaran dalam Islam, termasuk di dalamnya Kalimah Thayyibah Asma'ul-Hiusna yang merupakan penjabaran ataupun penafsiran dari salah satu ayat dari surat Al-Isra' serta penjabaran suatu hadits Nabi Muhammad saw, merupakan nama-nama yang baik yang diambil dari sifat-sifat Tuhan yang berjumlah 99. Meskipun terdapat beberapa lafadz yang tidak sama atau tidak sesuai dengan apa yang disebutkan dalam hadits, tetapi dalam hal jumlah tidak mengalami perbedaan yaitu tetap 99, kalau pun ada itu hanya karena berbeda pendapat antara penyertaan atau tidak disertakan lafadz Allah dalam jumlah 99 tersebut

Setelah sederetan Asma'uf-Husna, dilanjutkan dengan penjelasan atau keterangan mengenai keberadaan Asma'ul-Husna tersebut, dan pada bagian terakhir dituliskan do'a-do'a agar dihindarkan dari kejahatan-kejahatan atau perbuatan yang tidak diridlai Allah, agar dilindungi dan diberi pertolongan oleh Allah swt, dan dapat diampuni dosa-dosanya.

Berdasarkan uraian inskripsi pada pintu makam Sunan Kudus dapat disimpulkan, bahwa makna yang terkandung di dalam inskripsi tersebut memiliki nilai-nilai sufistik yang sangat tinggi. Nilai tersebut adalah upaya penulisan inskripsi yang dimaksudkan agar para 
peziarah dan para pembaca inskripsi selalu dekat dengan Tuhan Dalam arti setelah tahu makna dari sifat-sifat tersebut, diharapkan dapat diserap yang selanjutnya sedapat mungkin berperilaku dengan sifat-sifat tersebut, sekiranya sifat-sifat tersebut dapat dijangkau oleh manusia.

Demikianlah nilai sufistik pada inskripsi pintu makam Sunan Kudus dapat dilihat pada nilai seni yang ada. Kaligrafi berhuruf dan berbahasa Arab yang mengenalkan sifat-sifat llahi menunjukkan seni yang tertuju kepada Yang Maha Memiliki Keindahan. Hal itu dimaksudkan agar kita mampu memahami makna nilai estetika dalam kebudayaan Islam sebagaimana terpancar dalam ajaran tasamwuf.

\section{Kepustakaan}

Abdul Hadi, WM. 1984. Sumbangangan Islam Bagi Kebudayaan Indonesia dan Tantangan Modernisme, Prisma, Nomor ekstra, LP3ES, Jakarta.

Al-Maliky, Asy-Syaikh Ahmad Ash-Shawy, 1988. Hasyiyah Ash-Shamy -Ala Tafsiril Jalalain, III, cet. I, Daar el-Fikr, Beirut.

Al-Maqdisi, Al-Husaini, Fathurrahman Lithalibi Ayaatil-Qur 'an, Daar El-Fikr, Beirut.

Ambary, Hasan Muarif. 1991. Makam-Makam Kesultanan dan , Para Wali Penyebar Islam di Pulau Jawa, Aspects of Indonesian Archaeology. No.12, jakarta.

An-Nawawy, Muhyiddin Abi Zakaria Yahya Bin Syaraf, Al-Adzkar, AlMa'arif, Bandung, Indonesia.

Departemen Agama, 1983/1984. Al-Quran dan Tafsirnya V, Juz $13,14,15$, Jakarta

Khadim al-Haramain as-Syarifain al-Malik Fahd, Al-Qur'an al-Karim wa Tarjamatuhu ilal-Lughati al-Indonesiyyah, Al-Quran dan Tarjamahnya 
Nasution, Harun, 1984: Islam Ditinjau Dari Berbagai Aspeknya, I, UI Press, Jakarta.

Saptono, Nanang, 1994/1995. Lambang-Lambang Tasawuf pada Ragam Hias Masjid Agung Demak, Kebudayaan, No. 8 Depdikbud, Jakarta.

Salim, Muhammad Ibrahim, 1991. Dibalik Nama-nama Allah, Gema Insani Press, Jakarta.

Sirajuddin,AR,D,1985. Seni Kaligrafi Islam, Pustaka Panjimas Jakarta

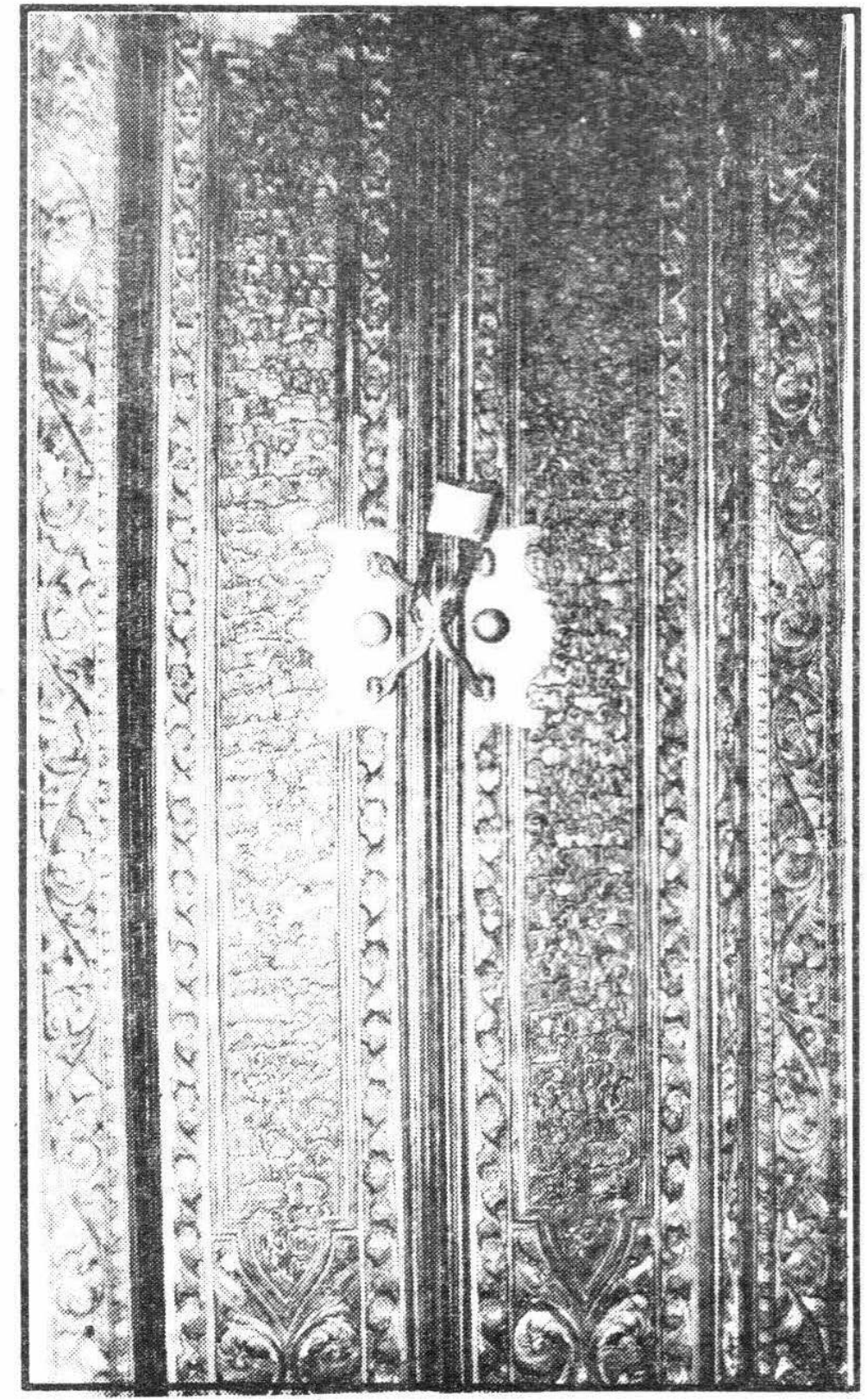

Inskripsi Pintu masuk Makam Sunan Kudus 